\title{
Article \\ A Comparison of Hypofractionated and Twice-Daily Thoracic Irradiation in Limited-Stage Small-Cell Lung Cancer: An Overlap-Weighted Analysis
}

\author{
Michael Yan ${ }^{1}$ D, Samantha Sigurdson ${ }^{1}{ }^{(D}$, Noah Greifer ${ }^{2}{ }^{\mathbb{D}}$, Thomas A. C. Kennedy ${ }^{1}$, Tzen S. Toh ${ }^{3,4}$, \\ Patricia E. Lindsay ${ }^{5,6}$, Jessica Weiss ${ }^{7}$, Katrina Hueniken ${ }^{4,7}$, Christy Yeung ${ }^{8}$, Vijithan Sugumar ${ }^{9}$, \\ Alexander Sun 5,6, Andrea Bezjak 5,6, B. C. John Cho 5,6, Srinivas Raman 5,6, Andrew J. Hope 5,6, \\ Meredith E. Giuliani ${ }^{5,6}$, Elizabeth A. Stuart ${ }^{2}$, Timothy Owen ${ }^{1}$, Allison Ashworth ${ }^{1}$, Andrew Robinson ${ }^{1}$, \\ Fabio Ynoe de Moraes ${ }^{1}$, Geoffrey Liu ${ }^{4,10,11}$ and Benjamin H. Lok $5,6,10,11, *$ (D)
}

Citation: Yan, M.; Sigurdson, S.; Greifer, N.; Kennedy, T.A.C.; Toh, T.S.; Lindsay, P.E.; Weiss, J.; Hueniken, K.; Yeung, C.; Sugumar, V.; et al. A Comparison of Hypofractionated and Twice-Daily Thoracic Irradiation in Limited-Stage Small-Cell Lung Cancer: An Overlap-Weighted Analysis. Cancers 2021, 13, 2895. https://doi.org/10.3390/ cancers 13122895

Academic Editor: Claus Belka

Received: 15 May 2021

Accepted: 4 June 2021

Published: 9 June 2021

Publisher's Note: MDPI stays neutral with regard to jurisdictional claims in published maps and institutional affiliations.

Copyright: (c) 2021 by the authors Licensee MDPI, Basel, Switzerland. This article is an open access article distributed under the terms and conditions of the Creative Commons Attribution (CC BY) license (https:// creativecommons.org/licenses/by/ $4.0 /)$
1 Department of Oncology, Cancer Centre of Southeastern Ontario, Queen's University, Kingston, ON K7L 5P9, Canada; michael.yan@kingstonhsc.ca (M.Y.); samantha.sigurdson@kingstonhsc.ca (S.S.); thomas.kennedy@kingstonhsc.ca (T.A.C.K.); timothy.owen@kingstonhsc.ca (T.O.); allison.ashworth@kingstonhsc.ca (A.A.); andrew.robinson@kingstonhsc.ca (A.R.); fabio.ynoedemoraes@kingstonhsc.ca (F.Y.d.M.)

2 Department of Mental Health, Bloomberg School of Public Health, Johns Hopkins University, Baltimore, MD 21205, USA; ngreife1@jhu.edu (N.G.); estuart@jhu.edu (E.A.S.)

3 The Medical School, University of Sheffield, Sheffield S10 2RX, UK; tzen.szen@gmail.com

4 Division of Medical Oncology and Hematology, Princess Margaret Cancer Centre, Toronto, ON M5G 2M9, Canada; Katrina.hueniken@uhnresearch.ca (K.H.); Geoffrey.Liu@uhn.ca (G.L.)

5 Radiation Medicine Program, Princess Margaret Cancer Centre, Toronto, ON M5G 2M9, Canada; Patricia.lindsay@rmp.uhn.ca (P.E.L.); Alex.Sun@rmp.uhn.ca (A.S.); andrea.bezjak@rmp.uhn.ca (A.B.); john.cho@rmp.uhn.ca (B.C.J.C.); srinivas.raman@rmp.uhn.ca (S.R.); andrew.hope@rmp.uhn.ca (A.J.H.); Meredith.Giuliani@rmp.uhn.ca (M.E.G.)

6 Department of Radiation Oncology, University of Toronto, Toronto, ON M5T 1P5, Canada

7 Department of Biostatistics, Princess Margaret Cancer Centre, Toronto, ON M5G 2M9, Canada; jessica.weiss@uhnresearch.ca

8 Department of Laboratory Medicine and Pathobiology, University of Toronto, Toronto, ON M5G 0A4, Canada; christy.yeung@mail.utoronto.ca

9 Department of Physiology and Pharmacology, Western University, London, ON N6A 5C1, Canada; vsuguma@uwo.ca

10 Institute of Medical Science, Faculty of Medicine, University of Toronto, Toronto, ON M5S 1A8, Canada

11 Department of Medical Biophysics, University of Toronto, Toronto, ON M5G 1L7, Canada

* Correspondence: Benjamin.Lok@rmp.uhn.ca; Tel.: +1-(416)-946-2919

Simple Summary: The optimal thoracic radiotherapy schedule for limited-stage small cell lung cancer (LS-SCLC) patients remains controversial. We conducted a propensity score adjusted analysis of LS-SCLC patients treated at our institutions with 40Gy/15 fractions versus 45Gy/30 twice daily. After overlap weighting for clinical and treatment variables and attaining good balance, we did not find a significant difference in overall survival, locoregional recurrence risk, thoracic response, or $\geq$ grade 3 toxicity. Moderate hypofractionation, with its similar outcomes and logistical advantages, may present a reasonable alternative to twice daily radiotherapy.

Abstract: Despite evidence for the superiority of twice-daily (BID) radiotherapy schedules, their utilization in practice remains logistically challenging. Hypofractionation (HFRT) is a commonly implemented alternative. We aim to compare the outcomes and toxicities in limited-stage small-cell lung cancer (LS-SCLC) patients treated with hypofractionated versus BID schedules. A bi-institutional retrospective cohort review was conducted of LS-SCLC patients treated with BID (45 Gy/30 fractions) or HFRT (40 Gy/15 fractions) schedules from 2007 to 2019. Overlap weighting using propensity scores was performed to balance observed covariates between the two radiotherapy schedule groups. Effect estimates of radiotherapy schedule on overall survival (OS), locoregional recurrence (LRR) risk, thoracic response, any $\geq$ grade 3 (including lung, and esophageal) toxicity were determined using multivariable regression modelling. A total of 173 patients were included in the overlap-weighted analysis, with 
110 patients having received BID treatment, and 63 treated by HFRT. The median follow-up was 20.4 months. Multivariable regression modelling did not reveal any significant differences in OS (hazard ratio [HR] 1.67, $p=0.38$ ), LRR risk (HR 1.48, $p=0.38$ ), thoracic response (odds ratio [OR] 0.23, $p=0.21$ ), any $\geq$ grade $3+$ toxicity (OR $1.67, p=0.33$ ), $\geq$ grade 3 pneumonitis (OR $1.14, p=0.84$ ), or $\geq$ grade 3 esophagitis (OR 1.41, $p=0.62$ ). HFRT, in comparison to BID radiotherapy schedules, does not appear to result in significantly different survival, locoregional control, or toxicity outcomes.

Keywords: small-cell lung cancer; hypofractionation; radiotherapy; propensity score

\section{Introduction}

Small-cell lung cancer is an aggressive histology of lung cancer with poor prognosis. Only about a third of patients have limited-stage disease (LS-SCLC) at diagnosis, with the potential to pursue curative intent treatment. Concurrent chemotherapy and radiation (CRT) remain a standard therapy in the management of patients with limited-stage smallcell lung cancer [1]. The addition of thoracic irradiation to chemotherapy has been shown to improve survival in this patient population [2].

Several trials have investigated the optimal radiotherapy schedule. Turrisi et al. compared hyperfractionated, twice-daily radiotherapy (BID) with a conventionally fractionated once-daily schedule, both to $45 \mathrm{~Gy}$. They established superior survival and disease-free survival with the former schedule, albeit with a higher rate of toxicities [3]. Subsequently, the CONVERT trial did not demonstrate superior survival with dose escalation of daily radiotherapy to 66 Gy when compared to the 45 Gy/30 BID schedule [4].

Despite these outcomes, adoption of BID regimens into clinical practice has been limited. Barriers include the logistical complexities from both a provider and patient perspective, as well as the potential for increased toxicity. Recent survey studies from Canada and the US report that only about a quarter of physicians routinely utilize BID schedules [5,6].

In contrast, hypofractionated radiotherapy (HFRT) schedules are frequently utilized. A small, phase 2 randomized trial comparing BID and HFRT did not show a significant survival difference between the two cohorts [7]. Further observational studies have supported the effectiveness of HFRT in comparison to BID [8], or conventional fractionation schedules in concurrent chemoradiotherapy [9].

One common HFRT schedule is 40 Gy in 15 daily fractions, initially established in a trial by the Canadian Cancer Trials Group (CCTG) [10]. This schedule is frequently used at our institutions, as well as nationally within Canada; despite the lack of comparative prospective evidence [5]. The objective of the current study is to compare the outcomes of LS-SCLC patients treated with HFRT versus BID schedules of CRT at two Canadian institutions, while employing the use of propensity score methods to better adjust for confounding variables.

\section{Materials and Methods}

\subsection{Data Sources}

We reviewed institutional databases from Princess Margaret Hospital (PMH) and Kingston Health Sciences Centre (KHSC) for patients with LS-SCLC who were treated with curative intent chemoradiation between January 2007 and November 2019. HFRT was routinely delivered at both institutions until 2006, in which, thereafter, BID began to be more regularly adopted into institutional practice. Generally, most suitable patients who were young and fit were offered BID treatment. Eligible patients may have declined due to logistical reasons, and opted for HFRT instead. A subset of patients received surgical resection upfront for solitary parenchymal disease or had been presumed to have non-SCLC; these patients received adjuvant chemoradiotherapy. Thoracic radiotherapy techniques varied from conventional to intensity-modulated radiotherapy (IMRT) and 
dependent on the era of treatment. All data were retrospectively acquired and managed using REDCAP electronic data capture tools [11]. This study was approved by the research ethics boards of both institutions.

Patients were excluded if they had extensive-stage disease, treated with palliative intent, or did not receive both chemotherapy and radiation. Furthermore, we only included patients treated with radiotherapy schedules of either $45 \mathrm{~Gy}$ in 30 twice-daily fractions (BID) or 40 Gy in 15 once-daily fractions (HFRT). Clinical, treatment, and outcomes details were retrospectively collected for all patients.

Clinical staging was determined using the 8th edition of the American Joint Committee on Cancer (AJCC) staging system [12]. Comorbidities were calculated using a modified Charlson Comorbidity Index (mCCI) score [13]. Radiotherapy was considered concurrent if the course was delivered prior to the final cycle of chemotherapy. Start of any treatment to end of radiotherapy (SER) was defined as the time in days from treatment start to the last thoracic radiotherapy fraction [14].

\subsection{Data Processing}

Missing covariate data were imputed using multiple imputation by chained equations, with all variables in the analysis used in the imputation procedure. Imputations were generated using random forest classification, and 200 imputations were generated. The fraction of missing data was $<5 \%$ for all variables, which is considered low [15].

\subsection{Propensity Score Methods and Diagnostics}

Various propensity score models were generated with radiotherapy schedule (BID vs. HFRT) as the treatment indicator (dependent variable). Age, gender, surgery utilization, stage, smoking status, smoking pack years, ECOG status, CCI score, pretreatment brain imaging modality, cycles of chemotherapy, concurrent versus sequential chemoradiation, SER, positron emission topography (PET) utilization, radiotherapy technique, image-guided radiotherapy (IGRT) utilization, and 4D-CT utilization were used as covariates (independent variables) in model generation. PCI utilization was not included in model generation, as the determination of offering PCI is dependent upon response to chemoradiation, and therefore is not independent of the effects of the radiotherapy schedule treatment variable. PCI utilization was, however, adjusted for in subsequent multivariable regression modelling, and independently analyzed for association with OS [16] Both matching and weighting methods were assessed, with the approach resulting in best covariate balance selected. A standardized mean difference (SMD) $<0.1$ is considered to indicate reasonably good balance [17].

Propensity score weights estimated as overlap weights were selected to be used in subsequent analyses as they resulted in the best covariate balance and effective sample size among the several attempted adjustment methods. Overlap weights allow us to estimate the average treatment effect in the overlap population (ATO), which corresponds to those patients approximately equally likely to receive either treatment (i.e., at clinical equipoise) $[18,19]$. Each patient's weight is proportional to the probability of that patient being assigned to the opposite radiotherapy group, so that patients who are less likely to be assigned to their actual group hold a greater weight than a patient who was more likely. For example, a patient treated in a more contemporary year (who would be more likely to have received BID treatment) would hold less weight if they had in actuality received BID treatment, and more weight if they were treated by HFRT.

Overlap weighting was performed individually within each imputed dataset. Effect estimates of the outcomes, described in the following section, were then obtained within each imputed dataset and combined across datasets using the multiple imputation combining rules. 


\subsection{Outcome Analysis}

Descriptive statistics were generated for the unweighted cohort. The Mann-Whitney $\mathrm{U}$ test and Fisher's exact test were used to compare continuous and categorical covariates between the BID and HFRT cohorts, respectively.

The primary outcome of interest was overall survival (OS). Secondary outcomes included locoregional recurrence (LRR) risk, thoracic response to chemoradiation, any grade 3 or greater toxicity, grade 3 or greater lung toxicity (LT), and grade 3 or greater esophageal toxicity (ET). Both unweighted and overlap-weighted analyses were performed for each endpoint.

OS curves were estimated using the Kaplan-Meier method, defined from the date of histologic diagnosis to the date of last follow-up or death from any cause. Differences in survival curves were evaluated using the adjusted log-rank test [20]. LRR risk was estimated from cumulative incidence functions based on sub-distribution hazards. LRR was defined from date of diagnosis to date of local or regional failure, whichever happened first; death without locoregional relapse was considered a competing event. Thoracic response was determined from radiological reporting and based on the RECIST 1.1 criteria [21]. Response was stratified into good response, consisting of complete or partial response (CR or PR), and poor response, consisting of stable or progressive disease (SD/PD). Toxicities were graded using the Common Terminology Criteria for Adverse Events (CTCAE) version 5 [22]. Lung toxicity and esophageal toxicity in the form of radiation pneumonitis and esophagitis, respectively, were assessed.

Univariable and multivariable regression analyses using the unweighted and overlapweighted cohorts were modelled for all endpoints. Covariates judged to be clinically associated with each outcome were determined a priori and included in the models. Cox proportional hazards regression was used to generate a model for OS. Fine-Gray competing risk regression was used to determine the effect estimate of the treatment variable on LRR risk [23]. Thoracic response to chemoradiation as well as $\geq$ grade 3 toxicities, including LT and ET events, were modelled using logistic regression. Robust standard errors were used to account for the weights.

\subsection{Sensitivity to Unobserved Confounding}

Sensitivity to unobserved confounding was assessed using e-values. The e-value represents the minimum magnitude of association, on a risk ratio scale, that a confounding variable not included in our models (unobserved confounding) must have with the treatment and outcome to alter our conclusions [24].

All statistical analyses were conducted in $R$ version 4.0.1 (R Foundation for Statistical Computing, Vienna, Austria). Multiple imputation was performed using the mice package, with estimated effects combined using the mitools (version 2.4) package [25,26]. Weighting was performed using the MatchThem (version 0.9.3) package [27]. Covariate balance was assessed using the cobalt (version 4.2.4) package. Survival analyses were performed using the survival (version 3.2.7) package [28]. E-values were assessed using the EValue (version 4.1.1) package [24].

\section{Results}

\subsection{Patient Characteristics}

A total of 229 patients with LS-SCLC were initially identified from the two institutional databases consecutively treated with curative intent between January 2007 and November 2019. After exclusions, 173 patients were eligible for overlap-weighting analysis, with 110 patients treated with BID fractionation and 63 treated with HFRT (Figure 1). The median follow-up for the entire cohort was 20.4 months from diagnosis to censoring. 


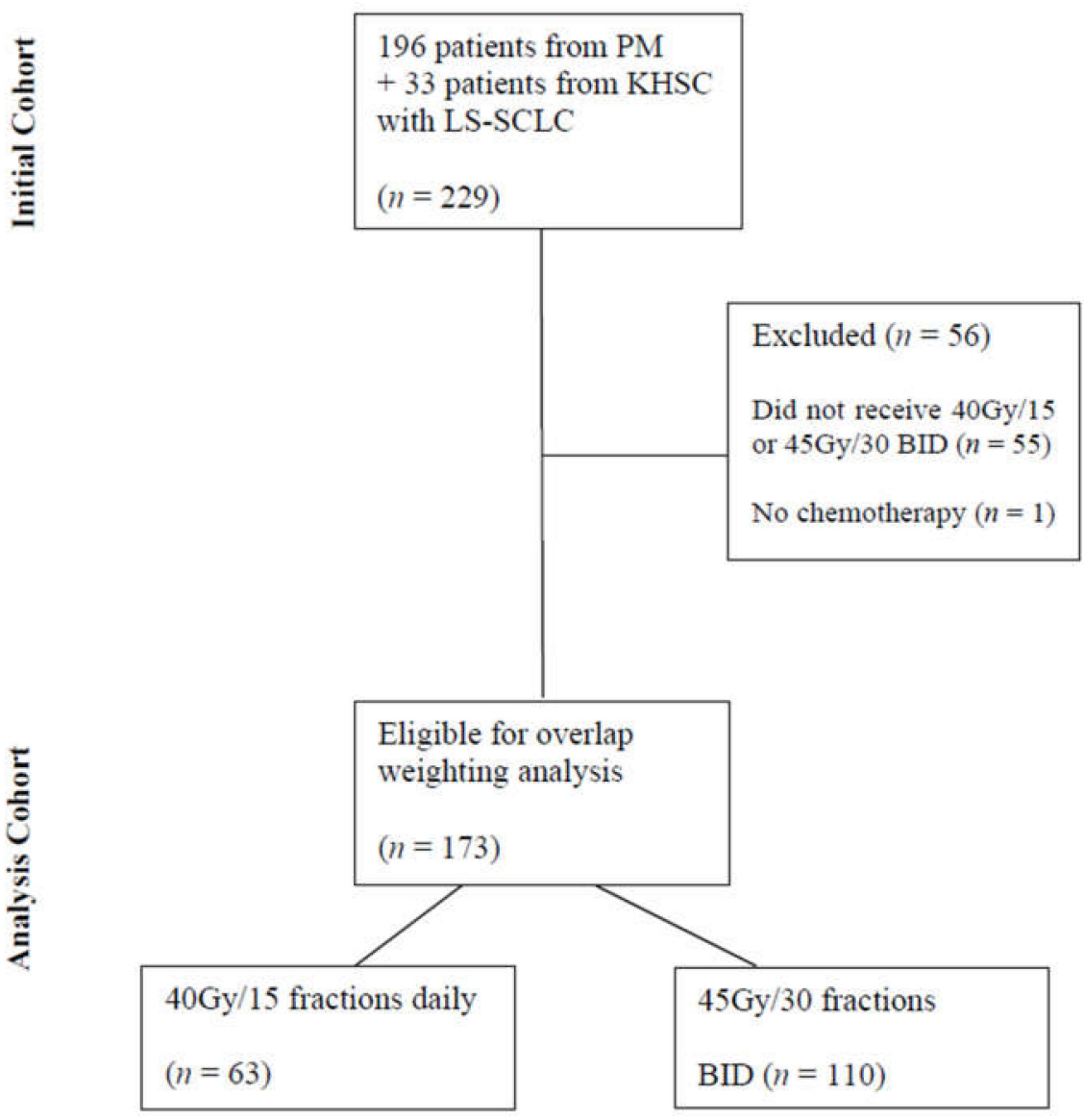

Figure 1. Flow Diagram Detailing Patient Selection. Abbreviations: PM-Princess Margaret Hospital, KHSC — Kingston Health Sciences Centre, LS-SCLC—-limited-stage small-cell lung cancer, BID— twice daily.

\subsection{Overlap Weighting}

Baseline characteristics for the cohort as well as their balance are summarized in Table 1. In unweighted analyses, patients receiving BID radiotherapy were more likely to have PET scans, later year of diagnosis, concurrent chemotherapy, IGRT, IMRT, and shorter SER. Of note, PCI use was not significantly different between the two cohorts, with $73 \%$ and $65 \%$ of patients having received PCI in the BID and HFRT cohorts, respectively $(p=0.26)$.

Table 1. Baseline Characteristics of Original and Weighted Cohorts.

\begin{tabular}{|c|c|c|c|c|c|c|}
\hline Variables & All $(n=173)$ & $\begin{array}{c}45 \text { Gy/30 Fractions } \\
\text { BID }(n=110)\end{array}$ & $\begin{array}{c}40 \mathrm{~Gy} / 15 \text { Fractions } \\
(n=63)\end{array}$ & $p$-Value & $\begin{array}{c}\text { Pre- } \\
\text { Weighting } \\
\text { SMD * }\end{array}$ & $\begin{array}{c}\text { Post- } \\
\text { Weighting } \\
\text { SMD * }\end{array}$ \\
\hline Age (mean, SD) & $66.7(9.7)$ & $65.7(8.9)$ & $68.5(10.8)$ & 0.12 & 0.33 & 0.001 \\
\hline Gender $(n, \%)$ & & & & 0.59 & 0.04 & 0 \\
\hline Male & $98(57)$ & $64(58)$ & $34(54)$ & & & \\
\hline Female & $75(43)$ & $46(42)$ & $29(46)$ & & & \\
\hline Surgery $(n, \%)$ & & & & 0.03 & 0.09 & 0 \\
\hline Yes & $12(7)$ & $4(4)$ & $8(13)$ & & & \\
\hline No & $161(93)$ & $106(96)$ & $55(87)$ & & & \\
\hline $\operatorname{ECOG}(n, \%)$ & & & & 0.80 & 0.65 & 0 \\
\hline 0 & $47(27)$ & $29(26)$ & $18(29)$ & & & \\
\hline
\end{tabular}


Table 1. Cont.

\begin{tabular}{|c|c|c|c|c|c|c|}
\hline Variables & All $(n=173)$ & $\begin{array}{l}45 \text { Gy/30 Fractions } \\
\text { BID }(n=110)\end{array}$ & $\begin{array}{c}40 \mathrm{~Gy} / 15 \text { Fractions } \\
(n=63)\end{array}$ & $p$-Value & $\begin{array}{c}\text { Pre- } \\
\text { Weighting } \\
\text { SMD * }\end{array}$ & $\begin{array}{c}\text { Post- } \\
\text { Weighting } \\
\text { SMD * }\end{array}$ \\
\hline 1 & $84(49)$ & $56(51)$ & $28(44)$ & & & \\
\hline 2 & $33(19)$ & $19(17)$ & $14(22)$ & & & \\
\hline 3 & $9(5)$ & $6(6)$ & $3(5)$ & & & \\
\hline Stage $(n, \%)$ & & & & 0.13 & 0.13 & 0 \\
\hline IA & $16(9)$ & $5(4)$ & $11(17)$ & & & \\
\hline IB & $5(3)$ & $1(2)$ & $3(5)$ & & & \\
\hline IIA & $5(3)$ & $3(3)$ & $2(3)$ & & & \\
\hline IIB & $11(6)$ & $8(8)$ & $3(5)$ & & & \\
\hline IIIA & $51(29)$ & $35(32)$ & $16(25)$ & & & \\
\hline IIIB & $58(34)$ & $39(36)$ & $19(30)$ & & & \\
\hline IIIC & $27(16)$ & $18(16)$ & $9(14)$ & & & \\
\hline $\begin{array}{l}\text { Year of Treatment } \\
\text { (median, IQR) }\end{array}$ & $\begin{array}{c}2013 \\
(2009-2016)\end{array}$ & 2014 (2010-2016) & 2011 (2008-2016) & 0.02 & 0.17 & 0 \\
\hline $\begin{array}{l}\text { Smoking Status } \\
\qquad(n, \%)\end{array}$ & & & & 1.0 & 0.005 & 0 \\
\hline $\begin{array}{l}\text { Never/Not } \\
\text { Documented }\end{array}$ & $6(3)$ & $4(4)$ & $2(3)$ & & & \\
\hline Former & $112(65)$ & $71(64)$ & $41(65)$ & & & \\
\hline Current & $55(32)$ & $35(32)$ & $20(31)$ & & & \\
\hline $\begin{array}{l}\text { Pack Years (mean, } \\
\text { SD) }\end{array}$ & $43.34(21.52)$ & $41.91(21.66)$ & $45.84(21.22)$ & 0.16 & 0.18 & 0 \\
\hline $\begin{array}{c}\text { Paraneoplastic } \\
\text { Syndrome }(n, \%)\end{array}$ & & & & 0.89 & 0.007 & 0.003 \\
\hline Yes & $20(12)$ & $13(12)$ & $7(11)$ & & & \\
\hline No & $153(88)$ & $97(88)$ & $56(89)$ & & & \\
\hline $\begin{array}{c}\operatorname{mCCI} \text { Score }(n, \\
\%)\end{array}$ & & & & 0.79 & 0.05 & 0 \\
\hline 0 & $114(66)$ & $74(67)$ & $40(64)$ & & & \\
\hline 1 & $47(27)$ & $28(25)$ & $19(30)$ & & & \\
\hline $2+$ & $12(7)$ & $8(7)$ & $4(6)$ & & & \\
\hline $\begin{array}{c}\text { PET-CT scan }(n, \\
\%)\end{array}$ & & & & $<0.01$ & 0.25 & 0 \\
\hline Yes & $96(55)$ & $71(65)$ & $25(40)$ & & & \\
\hline No & 77 (45) & 39 (35) & $38(60)$ & & & \\
\hline $\begin{array}{c}\text { Pre-treatment } \\
\text { Brain Imaging }(n, \\
\%)\end{array}$ & & & & 0.35 & 0.06 & 0 \\
\hline None & $1(1)$ & $0(0)$ & $1(1)$ & & & \\
\hline $\mathrm{CT}$ & $45(26)$ & $27(25)$ & $18(29)$ & & & \\
\hline MRI & 127 (73) & $83(75)$ & $44(70)$ & & & \\
\hline $\begin{array}{l}\text { 4D-CT Utilization } \\
\qquad(n, \%)\end{array}$ & & & & 0.48 & 0.01 & 0 \\
\hline
\end{tabular}


Table 1. Cont.

\begin{tabular}{|c|c|c|c|c|c|c|}
\hline Variables & All $(n=173)$ & $\begin{array}{c}45 \text { Gy/30 Fractions } \\
\text { BID }(n=110)\end{array}$ & $\begin{array}{c}40 \mathrm{~Gy} / 15 \text { Fractions } \\
(n=63)\end{array}$ & $p$-Value & $\begin{array}{c}\text { Pre- } \\
\text { Weighting } \\
\text { SMD * }\end{array}$ & $\begin{array}{c}\text { Post- } \\
\text { Weighting } \\
\text { SMD * }\end{array}$ \\
\hline Yes & $158(91)$ & $101(92)$ & $57(90)$ & & & \\
\hline No & $15(9)$ & $9(8)$ & $6(10)$ & & & \\
\hline $\begin{array}{c}\text { Treatment } \\
\text { Technique }(n, \%)\end{array}$ & & & & 0.01 & 0.20 & 0 \\
\hline 3D-CRT & $22(13)$ & $9(8)$ & $13(21)$ & & & \\
\hline IMRT & $135(76)$ & $92(84)$ & $40(63)$ & & & \\
\hline VMAT & $19(11)$ & $9(8)$ & $10(16)$ & & & \\
\hline $\begin{array}{l}\text { IGRT Utilization } \\
\qquad(n, \%)\end{array}$ & & & & $<0.01$ & 0.24 & 0 \\
\hline Non-IGRT & $39(23)$ & $16(15)$ & $23(37)$ & & & \\
\hline CBCT & $134(77)$ & $94(85)$ & $40(63)$ & & & \\
\hline $\begin{array}{l}* * \text { PCI Utilization } \\
(n, \%)\end{array}$ & & & & 0.29 & & \\
\hline Yes & $121(70)$ & $80(73)$ & $41(65)$ & & & \\
\hline No & $52(30)$ & $30(27)$ & $22(35)$ & & & \\
\hline $\begin{array}{c}\text { Chemotherapy }(n, \\
\%)\end{array}$ & & & & $<0.01$ & 0.15 & 0 \\
\hline Concurrent & 154 (89) & 104 (95) & $50(79)$ & & & \\
\hline Sequential & $19(11)$ & $6(5)$ & $13(21)$ & & & \\
\hline $\begin{array}{c}\text { Cycles of } \\
\text { Chemotherapy }(n, \\
\%)\end{array}$ & & & & 0.12 & 0.36 & 0.03 \\
\hline 0 & $1(1)$ & $0(0)$ & $1(2)$ & & & \\
\hline 1 & $3(2)$ & $1(1)$ & $2(3)$ & & & \\
\hline 2 & $9(5)$ & $6(5)$ & $3(5)$ & & & \\
\hline 3 & $9(5)$ & $3(3)$ & $6(10)$ & & & \\
\hline 4 & $63(36)$ & $37(34)$ & $26(41)$ & & & \\
\hline 5 & $18(10)$ & $13(12)$ & $5(8)$ & & & \\
\hline 6 & $70(40)$ & $50(45)$ & $20(32)$ & & & \\
\hline $\begin{array}{l}\text { Chemotherapy to } \\
\text { RT Time in Days } \\
\text { (mean, SD) }\end{array}$ & $56.05(36.80)$ & $50.71(32.37)$ & $65.38(42.14)$ & 0.05 & 0.31 & 0 \\
\hline
\end{tabular}

Abbreviations: BID—twice daily, ECOG—Eastern Cooperative Oncology Group, mCCI—modified Charlson Comorbidity Index, IQR— interquartile range, PET—positron emission tomography, 4D-CT-4-dimensional computed tomography, VMAT-volumetric modulated arc therapy, IMRT—intensity modulated radiotherapy, 3D-CRT-3-dimensional conformal radiotherapy, IGRT-image guided radiotherapy, KV-KV—orthogonal kV films, CBCT—cone beam CT, PCI—prophylactic cranial irradiation, SMD—standardized mean difference; * Note that for non-continuous covariates, the displayed SMD is the largest applied across all categorical levels. ${ }^{* *} \mathrm{PCI}$ was not included in covariate balancing since its utilization is determined after the treatment variable, thoracic radiotherapy, has been administered; ${ }^{* * *} p$-values determined from Mann-Whitney U test and Fisher's exact test for continuous and categorical variables respectively.

After overlap weighting, all covariates achieved exact mean balance with SMDs of 0 . Minimal residual imbalances (all SMDs $<0.05$ ) were observed in the square and cube of cycles of chemotherapy, and the cube of paraneoplastic syndrome and age (Figure S1) [19]. 


\subsection{Overall Survival}

There was no significant difference in OS between patients in the BID and HFRT treatment groups $(p=0.93)$ in the unweighted analysis. The 5 -year OS was $27.0 \%(95 \%$ CI, 20.1-36.3), 25.5\% (95\% CI, 17.1-37.9), and 29.3\% (95\% CI, 18.5-46.3\%) for all, BID, and HFRT patients, respectively (Figure 2A).

After overlap weighting, the 5-year OS was $24.3 \%$ (95\% CI, 16.1-36.6) for all patients, and $22.1 \%$ (95\% CI, 12.7-38.5) and 26.6\% (95\% CI, 14.4-49.0\%) for BID and HFRT cohorts, respectively. Again, there was no significant differences between the OS curves of the two cohorts $(p=0.93)$ (Figure 2B).

When stratifying by PCI use, there was a significant difference in OS between patients who received PCI and those who did not in the HFRT cohort $(p=0.004)$. This was not observed in the BID cohort $(p=0.4)$. However, after overlap weighting, there was no significant difference observed in either cohort (BID $p=0.09$; HFRT $p=0.61$ ) (Figure S2).

The proportional hazards assumption was not violated for any included covariates in the regression modelling of OS. Univariable and multivariable cox regression was performed adjusting for age, PCI utilization, ECOG status, cycles of chemotherapy, stage, SER, concurrent or sequential chemoradiation, and mCCI score. The results did not reveal any significant differences in OS between BID- and HFRT-treated patients in both unweighted and weighted analyses (Table 2).
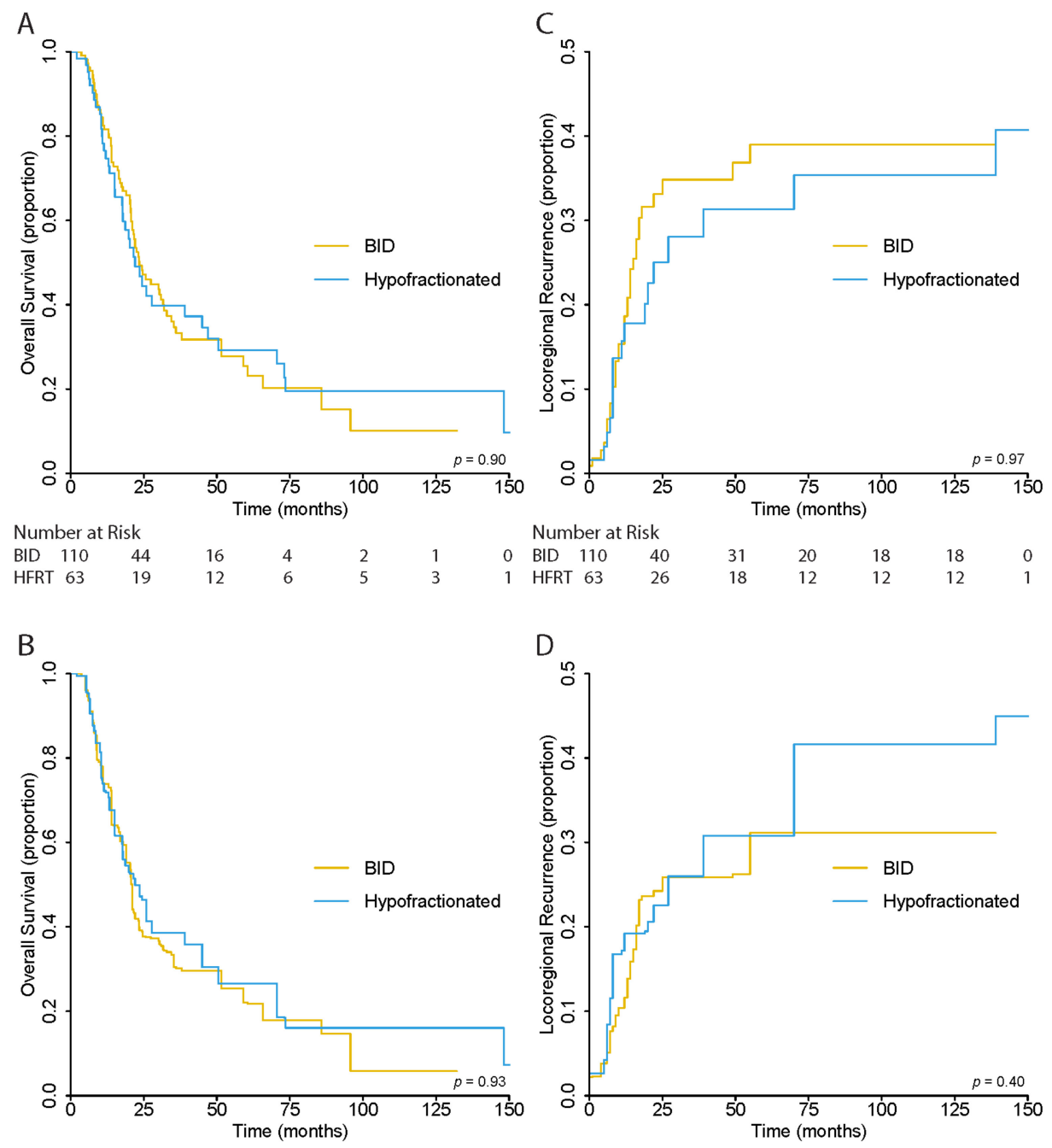

Figure 2. (A) Unweighted and (B) Overlap-Weighted Kaplan-Meier Estimates for Overall Survival and (C) Unweighted and (D) Overlap-Weighted Cumulative Incidence Functions for Locoregional Recurrence Risk. 
Table 2. Univariable and Multivariable Regression Models for Radiotherapy Schedule Effect on Outcomes in Weighted and Unweighted Populations (HFRT versus BID [reference]).

\begin{tabular}{|c|c|c|c|c|c|c|c|c|}
\hline \multirow{3}{*}{ Outcome } & \multicolumn{4}{|c|}{ Unweighted } & \multicolumn{4}{|c|}{ Overlap Weighted } \\
\hline & \multicolumn{2}{|c|}{ Univariable } & \multicolumn{2}{|c|}{ Multivariable } & \multicolumn{2}{|c|}{ Univariable } & \multicolumn{2}{|c|}{ Multivariable } \\
\hline & $\begin{array}{l}\text { HR/OR }(95 \% \\
\text { CI) }\end{array}$ & $p$-Value & $\begin{array}{c}\text { HR/OR }(95 \% \\
\text { CI) }\end{array}$ & $p$-Value & $\begin{array}{l}\text { HR/OR (95\% } \\
\text { CI) }\end{array}$ & $p$-Value & $\begin{array}{c}\text { HR/OR }(95 \% \\
\text { CI) }\end{array}$ & $p$-Value \\
\hline OS & $0.84(0.48-1.51)$ & 0.57 & $0.72(0.36-1.40)$ & 0.32 & $1.16(0.58-2.29)$ & 0.67 & $1.67(0.70-3.95)$ & 0.25 \\
\hline LRR risk & $0.86(0.49-1.53)$ & 0.62 & $1.33(0.64-2.75)$ & 0.44 & $1.29(0.61-2.72)$ & 0.51 & $1.48(0.62-3.54)$ & 0.38 \\
\hline $\begin{array}{l}\text { Thoracic } \\
\text { Response }\end{array}$ & $\begin{array}{c}3.89 \\
(1.12-13.57)\end{array}$ & 0.03 & $1.00(0.22-4.64)$ & 1.00 & $1.00(0.01-4.73)$ & 1.00 & $0.23(0.02-2.23)$ & 0.21 \\
\hline
\end{tabular}

Abbreviations: HFRT—hypofractionated radiotherapy, BID—twice-daily radiotherapy, CI—confidence interval, OS-overall survival, LRR—-locoregional recurrence, OR—odds ratio, HR—hazard ratio.

\subsection{Locoregional Recurrence Risk}

As in OS, there was no significant difference in LRR risk between BID and HFRT cohorts in the unweighted $(p=0.96)$ and overlap-weighted $(p=0.40)$ analysis. In the unweighted analysis, the 5-year LRR risk was 63.6\% (95\% CI, 55.8-72.5) for all patients, $61.0 \%$ (95\% CI, 51.4-72.5) for BID, and 68.7\% (95\% CI, 56.6-83.3) for the HFRT cohort (Figure 2C). In the weighted analysis, the risk was 68.9\% (95\% CI, 59.2-80.1), 68.9\% (95\% CI, 56.6-83.8), and 69.2\% (95\% CI, 55.3-86.6) for the same groups, respectively (Figure 2D).

Univariable and multivariable Fine-Gray competing risk regression was performed for unweighted and weighted analyses, adjusting for stage, cycles of chemotherapy, concurrent versus sequential chemotherapy, SER, and radiotherapy technique. There were no significant differences detected between the two radiotherapy cohorts (Table 2).

\subsection{Thoracic Response to Chemoradiotherapy}

A total of 161 patients (93\%) had a good response to CRT, with 106 (96.4\%) having received BID fractionation and $55(87.3 \%)$ receiving HFRT in the unweighted analysis. There was a significantly higher proportion of good response observed in the BID compared to HFRT cohorts in the unweighted, univariable analysis $(p=0.03)$. However, after overlap weighting, this difference was no longer observed.

Similarly, after multivariable logistic regression analysis, adjusting for stage, cycles of chemotherapy, SER, concurrent versus sequential chemoradiation, and radiotherapy technique, there was no significant association between radiotherapy schedule and thoracic response, in both the unweighted and overlap-weighted analyses (Table 2).

\subsection{Toxicity}

In the unweighted cohort, any grade 3 or greater toxicity was experienced by 34 $(19.7 \%)$ patients, with $20(18 \%)$ in the BID cohort and $14(22 \%)$ in the HFRT cohort. There was no significant difference in the incidence between the two cohorts $(p=0.52)$. One patient in the BID cohort experienced both $\geq$ grade 3 esophagitis and pneumonitis. The total incidence of $\geq$ grade 3 esophagitis occurred in $23(13 \%)$ patients, of which $14(12.7 \%)$ and 9 $(14.3 \%)$ were in the BID and HFRT cohorts, respectively. Again, there was no significant difference between the two groups $(p=0.77)$. Grade 3 or greater pneumonitis occurred in $12(7 \%)$ patients, of which $7(6 \%)$ were in the BID group and $5(8 \%)$ were in the HFRT group, with no significant difference $(p=0.70)$.

In both univariable and multivariable logistic regression, adjusting for stage, cycles of chemotherapy, IGRT use, concurrent versus sequential chemotherapy, and radiotherapy technique, there was no significant association between BID versus HFRT and any $\geq$ grade 3 toxicity, $\geq$ grade 3 esophagitis, or $\geq$ grade 3 pneumonitis. This was consistent between unweighted and overlap-weighted analyses (Table 3). 
Table 3. Univariable and Multivariable Regression Models for Radiotherapy Schedule Effect on Grade 3+ Toxicity in Weighted and Unweighted Populations (HFRT versus BID [reference]).

\begin{tabular}{ccccccccc}
\hline \multirow{2}{*}{ Toxicity } & \multicolumn{4}{c}{ Unweighted } & \multicolumn{3}{c}{ Overlap Weighted } \\
\cline { 2 - 9 } & \multicolumn{2}{c}{ Onivariable } & \multicolumn{2}{c}{ Multivariable } & \multicolumn{2}{c}{ Univariable } & \multicolumn{2}{c}{ Multivariable } \\
\cline { 2 - 9 } OR (95 CI) & $p$-Value & OR (95\% CI) & $p$-Value & OR (95\% CI) & $p$-Value & OR (95\% CI) & $p$-Value \\
\hline $\begin{array}{c}\text { Any } \\
\text { Toxicity }\end{array}$ & $1.29(0.14-0.36)$ & 0.52 & $1.31(0.59-2.89)$ & 0.51 & $1.62(0.58-4.53)$ & 0.36 & $1.67(0.59-4.72)$ & 0.33 \\
\hline Pulmonary & $1.29(0.39-4.27)$ & 0.68 & $1.16(0.31-4.30)$ & 0.82 & $1.06(0.25-4.50)$ & 0.93 & $1.14(0.32-4.10)$ & 0.84 \\
\hline Esophageal & $1.15(0.47-2.84)$ & 0.76 & $1.19(0.47-3.02)$ & 0.72 & $1.38(0.38-5.00)$ & 0.63 & $1.41(0.36-5.51)$ & 0.62 \\
\hline
\end{tabular}

Abbreviations: HFRT—hypofractionated radiotherapy, BID—twice daily radiotherapy, CI-confidence interval, OR-odds ratio.

\subsection{Sensitivity to Unobserved Confounding}

The E-value estimates for the effect of radiotherapy schedule on OS and LRR as determined from multivariable regression models in the overlap-weighted cohort were 1.91 and 1.95, respectively (Table S1). This suggests that only unobserved confounders with an association of nearly twofold, to both a patient's propensity for receiving a certain radiotherapy schedule (HFRT or BID) as well as the outcomes of OS and LRR, would be able to abrogate the observed HRs for each endpoint. Weaker confounding variables would not be able to do so. Our E-value estimates suggest that our overlap-weighted propensity score analysis is robust.

\section{Discussion}

Concurrent thoracic CRT is a critical component in the management of patients with LS-SCLC receiving curative intent treatment. The benefits of adding radiotherapy were established early on by a seminal meta-analysis of 13 randomized trials consisting of 2140 patients. Pignon et al. showed that, at 3 years, chemoradiation improved overall survival by $5.4 \%$ compared to chemotherapy alone [2]. Since then, trial efforts have shifted towards evaluating the details of chemoradiation; namely, the relative timing of the two modalities and the optimal dose fractionation.

\subsection{Establishment of BID as a Standard}

Due to the rapidly proliferating nature of the disease, it was hypothesized that accelerated schedules may result in improved outcomes. Turrisi et al. established the superiority of BID treatment in 1.5 Gy fractions over 3 weeks in a randomized trial compared to daily conventionally fractionated treatment with $1.8 \mathrm{~Gy}$ fractions over 5 weeks. Both arms were treated to $45 \mathrm{~Gy}$. The BID arm had superior survival, with a median OS of 23 months versus 19 months in the BID and daily arms, respectively $(p=0.04)$, albeit with higher rates of esophagitis [3]. One criticism of these results was the relatively lower biological equivalent dose (BED) given in the daily treatment arm as compared to BID treatment being delivered in a hyper-accelerated manner (i.e., more than 5 fractions per week) with greater BED. The CONVERT trial addressed this question by comparing the 45 Gy BID schema against a higher dose of $66 \mathrm{~Gy}$ in daily fractions. However, this trial did not show that daily fractionation was superior to BID fractionation. There was no significant difference in OS between the two arms $(p=0.14)$, although the median survival was nominally higher in the BID arm than the daily arm at 30 months versus 25 months, respectively [4]. Recently, a phase 2 randomized trial suggested a role for further dose escalation of twice-daily treatment. Grønberg et al. compared 60 Gy in 40 fractions BID with the conventional 45 Gy in 30 fractions BID, and found a survival difference at 2 years of $74.2 \%$ versus $48.1 \%$, respectively $(\mathrm{OR} 3.09, p=0.0005)$ [29]. 


\subsection{Patterns of Practice}

Despite high-level evidence, the BID regimen is not well adopted. A survey of Canadian radiation oncologists revealed that only about $30 \%$ of oncologists routinely prescribe 45 Gy/30 fractions BID for LS-SCLC patients, with the majority preferring 40 Gy/15 fractions [5]. Similarly, a more recent US survey found that more than three quarters of respondents prescribed daily treatment more commonly in their practice. The most common reasons for this were patient convenience, tolerability, and logistical simplicity. This survey also found that BID schedules were more frequently used in academic institutions [6]. This is corroborated by a National Cancer Database (NCDB) study in which BID utilization was found to be more likely in academic institutions (Odds Ratio [OR] 2.29, $p<0.001$ ). In total, only $11 \%$ of eligible patients received BID schedules [30].

\subsection{Evidence for HFRT}

One of the earliest prospective trials investigating radiotherapy timing in relation to chemotherapy utilized HFRT with $40 \mathrm{~Gy} / 15$ daily fractions; this provided prospective data with this fractionation schema [10]. From a biological stand point, the BED 10 of $40 \mathrm{~Gy} / 15$ ( $50.67 \mathrm{~Gy}$ ) is similar to that of $45 \mathrm{~Gy} / 30 \mathrm{BID}(51.75 \mathrm{~Gy})$, and therefore creates a plausible basis for comparability.

Subsequently, several retrospective studies support the use of HFRT thoracic radiotherapy schedules $[8,31]$. To date, only one prospective study, a phase 2 randomized control trial, compared BID and HFRT schedules head-to-head. Grønberg et al. randomized 157 patients, 84 patients to HFRT and 73 patients to BID, to be given concurrent with platinum-based chemotherapy. The study reported no significant difference in survival, with a median OS of 25 and 19 months in the BID and HFRT arms, respectively ( $p=0.61$ ). Similarly, no difference was observed in PFS or grade 3 toxicities. Patients treated with BID fractionation did, however, have high rates of complete response (33\% vs. $13 \%, p=0.003$ ). This is consistent with our observations in the unweighted, univariable analysis; however, this relationship was no longer observed after overlap weighting or multivariable adjustment. The authors conclude that no firm inferences could be drawn from the study, and that a larger phase 3 trial is needed [7].

Like others, the current study did not observe any significant difference in clinical outcomes between HFRT and BID schedules. The median OS was around 2 years for both cohorts, similar to literature values [7-10,32-34] (Table 4). Likewise, there was no difference in LRR risk between the two fractionation schemes. This is supported by a modeling study by Li et al., who found no difference in tumor control probability (TCP) in the form of 2-year freedom from locoregional progression, between BID (34\%) and HFRT (28\%) arms $(p=0.44)$ [35]. Our competing risk regression models predicted risks of $27 \%$ and $25 \%$ for the same fractionation cohorts, and similarly, did not observe a significant difference between the two $(p=0.57)$. The rate of $\geq$ grade 3 adverse events, in particular esophagitis and pneumonitis, were similar between the two cohorts. Again, this is replicated in the literature $[7,8]$. 
Table 4. Studies Including Patients with Limited-Stage Small-Cell Lung Cancer Treated with Hypofractionated Radiotherapy.

\begin{tabular}{|c|c|c|c|c|c|c|c|}
\hline \multirow[t]{2}{*}{ Author } & \multirow[t]{2}{*}{ Year } & \multirow[t]{2}{*}{$\begin{array}{l}\text { HFRT Schedule } \\
\text { (Gy/fx) }\end{array}$} & \multirow[t]{2}{*}{$n$} & \multicolumn{2}{|c|}{$\begin{array}{l}\text { Overall Survival } \\
(\%)\end{array}$} & \multirow{2}{*}{$\begin{array}{c}\geq \text { Grade } 3 \\
\text { Esophageal Toxicity } \\
(\%)\end{array}$} & \multirow[t]{2}{*}{$\begin{array}{l}\geq \text { Grade } 3 \text { Lung } \\
\text { Toxicity (\%) }\end{array}$} \\
\hline & & & & 2-Year & 5-Year & & \\
\hline Murray et al. [10] * & 1993 & $40 / 15$ & $155^{\#}$ & 40 & 20 & 43.6 & 3.2 \\
\hline Videtic et al. [32] & 2003 & $40 / 15$ & 122 & 27 & 9 & - & - \\
\hline Bettington et al. [8] & 2013 & $40 / 15$ & 38 & - & 20 & - & - \\
\hline Socha et al. [33] & 2015 & $42 / 15$ & 100 & 52 & 31 & 0 & 0 \\
\hline Grønberg et al. [7] & 2016 & $45 / 15$ & 84 & 42 & - & 31 & 6 \\
\hline $\begin{array}{c}\text { Turgeon et al. [31] } \\
*\end{array}$ & 2017 & $40 / 15$ & 68 & 53 & 35 & 9 & 1 \\
\hline Zhang et al. [34] & 2017 & $55 / 20$ & 69 & 62 & - & 12 & 10 \\
\hline Zayed et al. [9] & 2020 & $40-45 / 15-20$ & 56 & - & 26 & $6+$ & $3+$ \\
\hline Present study & 2020 & $40 / 15$ & 63 & 47 & 24 & 14 & 8 \\
\hline
\end{tabular}

Abbreviations: HFRT—hypofractionated, Gy—gray, fx-fractions, OS-overall survival, LRR-locoregional recurrence, GIgastrointestinal; * Randomized trials; ${ }^{\#}$ Only the early concurrent therapy arm is included.

\subsection{Potential Benefits of HFRT}

In the setting of comparable outcomes, HFRT presents additional benefits in comparison to BID schedules. Primarily, HFRT is easier to administer from a logistical standpoint for both patients and treating professionals [16,30,36]. Patients treated on BID schedules require at least a $6 \mathrm{~h}$ period in between fractions, which may take a physical, mental, and financial toll. The magnitude of effect of patient inconvenience in the selection of dose fractionation has yet to be formally evaluated from a patient standpoint, although previous survey data suggest that it is a primary consideration for radiation oncologists [6,37]. Secondly, the higher rates of toxicity observed in the Turrisi trial have introduced a persistent hesitancy in the universal adoption of BID treatment. A survey of experienced European radiation oncologists revealed that most institutions preferred once-daily treatment, albeit of conventional fractionation, for unfit patients $[16,36]$. However, toxicity may be similar between BID and HFRT, as suggested by the current analysis and previous studies, particularly in the advent of more precise radiotherapy technologies such as $4 \mathrm{D}-\mathrm{CT}$ simulation and IMRT $[7,8]$.

Furthermore, HFRT circumvents some of the concerns regarding accelerated repopulation that protracted radiotherapy schedules, such as 60-66 Gy in 30-33 fractions, may present $[38,39]$. It is well established that early administration of radiation concurrently with chemotherapy improves outcomes. However, the total duration of radiotherapy, defined as SER by De Ruysscher et al., showed that each week extension in SER was associated with a nearly $2 \%$ decrease in 5 -year OS in a meta-analysis [14]. Their subsequent individual patient meta-analysis also showed that "shorter or earlier" thoracic radiotherapy administration in comparison to "longer or later" was associated with a nearly $8 \%$ improvement in 5-year OS when comparing patients with similar chemotherapy adherence [40].

Nevertheless, despite its potential advantages, there is hesitancy in the recommendation of HFRT as a standard radiotherapy schedule in thoracic CRT for LS-SCLC patients. The recent ASTRO guidelines recommend $45 \mathrm{~Gy} / 30 \mathrm{BID}$ as a standard treatment, and that 60-70 Gy in conventional fractionation is an acceptable alternative. HFRT was not routinely recommended owing to the limited evidence for its equivalence [1]. Similarly, despite the opportunity for minimizing patient-viral exposure that HFRT presents, the COVID-19 ASTRO-ESTRO consensus guideline only recommends HFRT in late-phase pandemic conditions, when radiotherapy resources are limited [41]. 


\subsection{Strengths and Limitations}

The strengths of our study include our collection of a comprehensive set of covariates thought to potentially confound the effect of radiotherapy schedule on the outcomes of interest. We adjusted for these confounders using propensity score weighting and created a cohort with nearly perfect balance on covariates. E-value calculations demonstrate robust estimates of OS, LRR, and toxicity outcomes, in which only unobserved confounders of substantial magnitude could alter the observed associations.

Our study is inherently limited by its retrospective nature in terms of data quality, confounding, and generalizability. One covariate that was unavailable within our dataset was the extent of the target volume; however, our analyses did include AJCC stage, which is also representative of disease burden. We addressed observed confounding with adjustment using overlap weighting to balance measured covariates. Despite the E-value estimates, the possibility of unobserved confounding persists after overlap weighting and cannot be completely accounted for. Regarding generalizability, the effects estimated using the overlap weights generalize only to patients in the overlap population rather than to the LS-SCLC population as a whole. However, the impact of using overlap weights here on generalizability is minimal, as the distribution of patient characteristics in the overlap-weighted sample did not differ greatly from that in the original sample. In regards to missing covariate values, we utilized multiple imputation, which we recognize does not represent true data values and assumes that missing values do not depend on unobserved factors. However, the amount of missing data was small, and previous evidence suggests that it can be valid for covariates such as stage [42]. Lastly, we do caution the interpretation of the results, in that the lack of treatment effect between the two radiotherapy groups may be in part attributed to a lack in statistical power to determine a difference, rather than there truly being no difference. Nevertheless, previous literature supports the observed equivalence of BID and HFRT schedules [7,8,43].

\section{Conclusions}

Concurrent CRT with HFRT compared to BID radiotherapy did not show a difference in OS, LRR, or $\geq$ grade 3 toxicities in our propensity score adjusted LS-SCLC cohort. While BID treatment remains the gold standard, the use of HFRT as a suitable treatment schedule warrants consideration when clinically appropriate due to the shorter treatment duration and logistical benefits. Prospective study to establish the effectiveness or non-inferiority of HFRT in comparison to other radiotherapy schedules for LS-SCLC is merited.

Supplementary Materials: The following are available online at https:/ / www.mdpi.com/article/10 .3390/cancers13122895/s1, Figure S1: Love Plot with Standardized Mean Differences, Figure S2: (A) Unweighted and (B) Overlap-Weighted Kaplan-Meier Estimates for Overall Survival Stratified by PCI and Radiotherapy Schedule, Table S1: E-value for Multivariable Effect Estimates (HFRT versus BID [reference]).

Author Contributions: Conceptualization, M.Y., E.A.S., F.Y.d.M., and B.H.L.; methodology, M.Y., N.G., E.A.S., F.Y.d.M., and B.H.L.; software, M.Y., K.H., J.W., and N.G.; validation, P.E.L., A.S., A.B., B.C.J.C., S.R., A.J.H., M.E.G., G.L., T.O., A.A., A.R., and B.H.L.; formal analysis, M.Y., N.G., E.A.S., K.H., and J.W.; investigation, M.Y., S.S., and T.A.C.K.; resources, M.Y., C.Y., and K.H.; data curation, M.Y., S.S., T.A.C.K., T.S.T., C.Y., and V.S.; writing-original draft preparation, M.Y., N.G., and S.S.; writing-review and editing, all authors; visualization, M.Y.; supervision, F.Y.d.M. and B.H.L.; project administration, M.Y., G.L. and B.H.L.; funding acquisition, M.Y. All authors have read and agreed to the published version of the manuscript.

Funding: This research was supported by funding from the STARS21 Scholarship Program from the Terry Fox Foundation. G.L. acknowledges research support from the Lusi Wong Fund and Alan Brown Research Chair, both of the Princess Margaret Cancer Foundation. B.H.L. acknowledges research support from the Conquer Cancer Foundation of ASCO, International Association for the Study of Lung Cancer, Ontario Molecular Pathology Research Network of the Ontario Institute for Cancer Research, Lung Cancer Research Foundation, Canada Foundation for Innovation, Cancer 
Research Society, Canadian Institutes of Health Research, National Institute of Health/National Cancer Institute (U01CA253383), and the Clinical and Translational Science Center at Weill Cornell Medical Center and MSKCC (UL1TR00457).

Institutional Review Board Statement: The study was conducted according to the guidelines of the Declaration of Helsinki, and approved by the Institutional Review Boards of the University Health Network (06-0639) and Queen's University (6028441).

Informed Consent Statement: A wavier of informed consent for this study was provided by the Institutional Review Boards of the University Health Network and Queen's University.

Data Availability Statement: The datasets used in the current study are available from the corresponding author upon request.

Acknowledgments: The authors would like to thank Melania Pintilie and Peter Austin for their help with the development of code for competing risk regression in the setting of propensity score weighted adjustments.

Conflicts of Interest: B.H.L. reports honoraria and non-financial support from AstraZeneca. B.H.L. has received research funding from Pfizer and AstraZeneca not related to this work. No other authors have any pertinent disclosures.

\section{References}

1. Simone, C.B., 2nd; Bogart, J.A.; Cabrera, A.R.; Daly, M.E.; DeNuzio, N.J.; Detterbeck, F.; Faivre-Finn, C.; Gore, E.; Kruser, T.J.; Wu, A.J.; et al. Radiation Therapy for Small Cell Lung Cancer: An ASTRO Clinical Practice Guideline. Pract. Radiat. Oncol. 2020. [CrossRef]

2. Pignon, J.-P.; Arriagada, R.; Ihde, D.C.; Johnson, D.H.; Perry, M.C.; Souhami, R.L.; Brodin, O.; Joss, R.A.; Kies, M.S.; Lebeau, B.; et al. A meta-analysis of thoracic radiotherapy for small-cell lung cancer. N. Engl. J. Med. 1992, 327, 1618-1624. [CrossRef] [PubMed]

3. Turrisi, A.T., 3rd; Kim, K.; Blum, R.; Sause, W.T.; Livingston, R.B.; Komaki, R.; Wagner, H.; Aisner, S.; Johnson, D.H. Twicedaily compared with once-daily thoracic radiotherapy in limited small-cell lung cancer treated concurrently with cisplatin and etoposide. N. Engl. J. Med. 1999, 340, 265-271. [CrossRef] [PubMed]

4. Faivre-Finn, C.; Snee, M.; Ashcroft, L.; Appel, W.; Barlesi, F.; Bhatnagar, A.; Bezjak, A.; Cardenal, F.; Fournel, P.; Harden, S.V.; et al. Concurrent once-daily versus twice-daily chemoradiotherapy in patients with limited-stage small-cell lung cancer (CONVERT): An open-label, phase 3, randomised, superiority trial. Lancet Oncol. 2017, 18, 1116-1125. [CrossRef]

5. Shahi, J.; Wright, J.; Gabos, Z.; Swaminath, A. Management of Small-Cell Lung Cancer with Radiotherapy-A Pan-Canadian Survey of Radiation Oncologists. Curr. Oncol. 2016, 23, 184-195. [CrossRef]

6. Farrell, M.J.; Yahya, J.B.; Degnin, C.; Chen, Y.; Holland, J.M.; Henderson, M.A.; Jaboin, J.J.; Harkenrider, M.M.; Thomas, C.R.; Mitin, T. Radiation Dose and Fractionation for Limited-stage Small-cell Lung Cancer: Survey of US Radiation Oncologists on Practice Patterns. Clin. Lung Cancer 2019, 20, 13-19. [CrossRef] [PubMed]

7. Grønberg, B.H.; Halvorsen, T.O.; Fløtten, Ø.; Brustugun, O.T.; Brunsvig, P.F.; Aasebø, U.; Bremnes, R.M.; Tollåli, T.; Hornslien, K.; Aksnessæther, B.Y.; et al. Randomized phase II trial comparing twice daily hyperfractionated with once daily hypofractionated thoracic radiotherapy in limited disease small cell lung cancer. Acta Oncol. 2015, 55, 591-597. [CrossRef]

8. Bettington, C.S.; Tripcony, L.; Bryant, G.; Hickey, B.; Pratt, G.; Fay, M. A retrospective analysis of survival outcomes for two different radiotherapy fractionation schedules given in the same overall time for limited stage small cell lung cancer. J. Med. Imaging Radiat. Oncol. 2013, 57, 105-112. [CrossRef]

9. Zayed, S.; Chen, H.; Ali, E.; Rodrigues, G.B.; Warner, A.; Palma, D.A.; Louie, A.V. Is There a Role for Hypofractionated Thoracic Radiation Therapy in Limited-Stage Small Cell Lung Cancer? A Propensity Score Matched Analysis. Int. J. Radiat. Oncol. 2020, 108, 575-586. [CrossRef]

10. Murray, N.; Coy, P.; Pater, J.L.; Hodson, I.; Arnold, A.; Zee, B.C.-Y.; Payne, D.; Kostashuk, E.C.; Evans, W.K.; Dixon, P.; et al. Importance of timing for thoracic irradiation in the combined modality treatment of limited-stage small-cell lung cancer. J. Clin. Oncol. 1993, 11, 336-344. [CrossRef]

11. Harris, P.A.; Taylor, R.; Thielke, R.; Payne, J.; Gonzalez, N.; Conde, J.G. Research electronic data capture (REDCap)—A metadatadriven methodology and workflow process for providing translational research informatics support. J. Biomed. Inform. 2009, 42, 377-381. [CrossRef]

12. Rami-Porta, R.; Bolejack, V.; Giroux, D.J.; Chansky, K.; Crowley, J.; Asamura, H.; Goldstraw, P. The IASLC Lung Cancer Staging Project: The New Database to Inform the Eighth Edition of the TNM Classification of Lung Cancer. J. Thorac. Oncol. 2014, 9, 1618-1624. [CrossRef]

13. Quan, H.; Li, B.; Couris, C.M.; Fushimi, K.; Graham, P.; Hider, P.; Januel, J.-M.; Sundararajan, V. Updating and Validating the Charlson Comorbidity Index and Score for Risk Adjustment in Hospital Discharge Abstracts Using Data From 6 Countries. Am. J. Epidemiol. 2011, 173, 676-682. [CrossRef] 
14. De Ruysscher, D.; Pijls-Johannesma, M.; Bentzen, S.M.; Minken, A.; Wanders, R.; Lutgens, L.; Hochstenbag, M.; Boersma, L.; Wouters, B.; Lammering, G.; et al. Time Between the First Day of Chemotherapy and the Last Day of Chest Radiation Is the Most Important Predictor of Survival in Limited-Disease Small-Cell Lung Cancer. J. Clin. Oncol. 2006, 24, 1057-1063. [CrossRef]

15. Graham, J.W. Missing Data Analysis: Making It Work in the Real World. Annu. Rev. Psychol. 2009, 60, 549-576. [CrossRef] [PubMed]

16. Woolf, D.; Slotman, B.; Faivre-Finn, C. The Current Role of Radiotherapy in the Treatment of Small Cell Lung Cancer. Clin. Oncol. 2016, 28, 712-719. [CrossRef]

17. Stuart, E.A. Matching Methods for Causal Inference: A Review and a Look Forward. Stat. Sci. 2010, 25, 1-21. [CrossRef]

18. Thomas, E.L.; Li, F.; Pencina, M.J. Overlap Weighting: A Propensity Score Method That Mimics Attributes of a Randomized Clinical Trial. JAMA 2020, 323, 2417-2418. [CrossRef]

19. Mao, H.; Li, L.; Greene, T. Propensity score weighting analysis and treatment effect discovery. Stat. Methods Med. Res. 2018, 28, 2439-2454. [CrossRef]

20. Xie, J.; Liu, C. Adjusted Kaplan-Meier estimator and log-rank test with inverse probability of treatment weighting for survival data. Stat. Med. 2005, 24, 3089-3110. [CrossRef] [PubMed]

21. Schwartz, L.H.; Litière, S.; De Vries, E.; Ford, R.; Gwyther, S.; Mandrekar, S.; Shankar, L.; Bogaerts, J.; Chen, A.; Dancey, J.; et al. RECIST 1.1-Update and clarification: From the RECIST committee. Eur. J. Cancer 2016, 62, 132-137. [CrossRef] [PubMed]

22. U.S Department of Health and Human Services. Common Terminology Criteria for Adverse Events. Version 5; 2017. Available online: https:/ / ctep.cancer.gov/protocoldevelopment/electronic_applications/docs/ctcae_v5_quick_reference_5x7.pdf (accessed on 10 January 2021).

23. Fine, J.P.; Gray, R.J. A Proportional Hazards Model for the Subdistribution of a Competing Risk. J. Am. Stat. Assoc. 1999, 94, 496-509. [CrossRef]

24. VanderWeele, T.J.; Ding, P. Sensitivity Analysis in Observational Research: Introducing the E-Value. Ann. Intern. Med. 2017, 167, 268-274. [CrossRef] [PubMed]

25. Van Burren, S.; Groothuis-Oudshoorn, K. Mice: Multivariate Imputation by Chained Equations in R. J. Stat. Softw. 2011, 45, 1-67.

26. Lumley, T. Mitools: Tools for Multiple Imputation of Missing Data. 2019. Available online: https://cran.r-project.org/web/ packages/mitools/mitools.pdf (accessed on 20 January 2021).

27. Pishgar, F.; Greifer, N. MatchThem: Matching and Weighting Multiply Imputed Datasets. arXiv 2009.

28. Therneau, T.M.; Grambsch, P.M. Modeling Survival Data: Extending the Cox Model; Springer: New York, NY, USA, 2000.

29. Grønberg, B.H.; Killingberg, K.T.; Fløtten, Ø.; Brustugun, O.T.; Hornslien, K.; Madebo, T.; Langer, S.W.; Schytte, T.; Nyman, J.; Risum, S.; et al. High-dose versus standard-dose twice-daily thoracic radiotherapy for patients with limited stage small-cell lung cancer: An open-label, randomised, phase 2 trial. Lancet Oncol. 2021, 22, 321-331. [CrossRef]

30. Schreiber, D.; Wong, A.T.; Schwartz, D.; Rineer, J. Utilization of Hyperfractionated Radiation in Small-Cell Lung Cancer and Its Impact on Survival. J. Thorac. Oncol. 2015, 10, 1770-1775. [CrossRef] [PubMed]

31. Turgeon, G.; Souhami, L.; Kopek, N.; Hirsh, V.; Ofiara, L.; Faria, S. Thoracic irradiation in 3 weeks for limited-stage small cell lung cancer: Is twice a day fractionation really needed? Cancer/Radiothér. 2017, 21, 89-98. [CrossRef]

32. Videtic, G.M.M.; Truong, P.T.; Dar, A.R.; Ye, E.W.; Stitt, L.W. Shifting from hypofractionated to "conventionally" fractionated thoracic radiotherapy: A single institution's 10-year experience in the management of limited-stage small-cell lung cancer using concurrent chemoradiation. Int. J. Radiat. Oncol. Biol. Phys. 2003, 57, 709-716. [CrossRef]

33. Socha, J.; Guzowska, A.; Tyc-Szczepaniak, D.; Wierzchowski, M.; Sprawka, A.; Szczesna, A.; Kepka, L. Accelerated hypofractionated thoracic radiotherapy in limited disease small cell lung cancer: Comparison with the results of conventionally fractionated radiotherapy. J. BUON 2015, 20, 146-157.

34. Zhang, J.; Fan, M.; Liu, D.; Zhao, K.-L.; Wu, K.-L.; Zhao, W.-X.; Zhu, Z.-F.; Fu, X.-L. Hypo- or conventionally fractionated radiotherapy combined with chemotherapy in patients with limited stage small cell lung cancer. Radiat. Oncol. 2017, 12, 51. [CrossRef]

35. Li, Q.-W.; Qiu, B.; Wang, B.; Zhang, J.; Chen, L.; Zhou, Y.; Qin, J.-K.; Guo, S.-P.; Xie, W.-H.; Hui, Z.-G.; et al. Comparison of hyperand hypofractionated radiation schemes with IMRT technique in small cell lung cancer: Clinical outcomes and the introduction of extended LQ and TCP models. Radiother. Oncol. 2019, 136, 98-105. [CrossRef] [PubMed]

36. Glatzer, M.; Faivre-Finn, C.; De Ruysscher, D.; Widder, J.; Van Houtte, P.; Troost, E.G.; Dahele, M.R.; Slotman, B.J.; Ramella, S.; Pöttgen, C.; et al. Once daily versus twice-daily radiotherapy in the management of limited disease small cell lung cancerDecision criteria in routine practise. Radiother. Oncol. 2020, 150, 26-29. [CrossRef] [PubMed]

37. Katz, M.S.; Fernández, C.; Simcock, R. CONVERTed or not: What are the barriers to implementing the evidence? Lancet Oncol. 2017, 18, e627. [CrossRef]

38. Brade, A.M.; Tannock, I.F. Scheduling of Radiation and Chemotherapy for Limited-Stage Small-Cell Lung Cancer: Repopulation as a Cause of Treatment Failure? J. Clin. Oncol. 2006, 24, 1020-1022. [CrossRef]

39. Withers, H.R.; Taylor, J.M.G.; Maciejewski, B. The hazard of accelerated tumor clonogen repopulation during radiotherapy. Acta Oncol. 1988, 27, 131-146. [CrossRef] [PubMed]

40. De Ruysscher, D.; Lueza, B.; Le Péchoux, C.; Johnson, D.H.; O’Brien, M.; Murray, N.; Spiro, S.; Wang, X.; Takada, M.; Lebeau, B.; et al. Impact of thoracic radiotherapy timing in limited-stage small-cell lung cancer: Usefulness of the individual patient data meta-analysis. Ann. Oncol. 2016, 27, 1818-1828. [CrossRef] [PubMed] 
41. Guckenberger, M.; Belka, C.; Bezjak, A.; Bradley, J.; Daly, M.E.; DeRuysscher, D.; Dziadziuszko, R.; Faivre-Finn, C.; Flentje, M.; Gore, E.; et al. Practice Recommendations for Lung Cancer Radiotherapy During the COVID-19 Pandemic: An ESTRO-ASTRO Consensus Statement. Int. J. Radiat. Oncol. 2020, 107, 631-640. [CrossRef]

42. Luo, Q.; Egger, S.; Yu, X.Q.; Smith, D.P.; O'Connell, D.L. Validity of using multiple imputation for "unknown" stage at diagnosis in population-based cancer registry data. PLoS ONE 2017, 12, e0180033. [CrossRef] [PubMed]

43. Sun, A.; Durocher-Allen, L.; Ellis, P.; Ung, Y.; Goffin, J.; Ramchandar, K.; Darling, G. Guideline for the Initial Management of Small Cell Lung Cancer (Limited and Extensive Stage) and the Role of Thoracic Radiotherapy and First-line Chemotherapy. Clin. Oncol. 2018, 30, 658-666. [CrossRef] 